\title{
Implementasi UU Nomor 39 Tahun 2004 terhadap Tenaga Kerja Indonesia di Luar Negeri
}

\author{
Implementation of Law Number 39 of 2004 Against \\ Indonesian Workers Abroad
}

\author{
Vinni Dini Pratiwi* \& Suharno
}

Jurusan Pendidikan Pancasila dan Kewarganegaraan, Program Pascasarjana Universitas Negeri Yogyakarta, Indonesia

Diterima: Januari 2019; Disetujui: Maret 2019; Dipublish: Juni 2019.

\begin{abstract}
Abstrak
Tenaga Kerja Indonesia (TKI) adalah sebutan untuk warga negara Indonesia yang bertubuh rendah dan tidak trampil yang bekerja di luar negeri dalam hubungan kerja untuk periode waktu tertentu dengan upah. Perlindungan hukum atas Hak-hak Tenaga Kerja Indonesia (TKI) belum berjalan dengan baik, perlunya pengarahan tentang makna hukum perburuhan untuk Indonesia, ini merongrong Tenaga Kerja Indonesia (TKI) dan menghilangkan keamanan kerja bagi tenaga indonesia saat di luar negeri, kendala implementasi perlindungan hukum Indonesia tenaga kerja adalah kesalahan yang dilakukan oleh Indonesia yaitu Tenaga Kerja tidak melaporkan masalah pada Pemerintah Indonesia sehubungan dengan pekerjaan Tenaga Kerja Indonesia (TKI). Tujuan dari penelitian ini adalah untuk mengetahui secara lebih jelas dan luas tentang perlindungan Tenaga Kerja Indonesia (TKI) yang bekerja di luar negeri yang dilakukan oleh teras Kementerian Penempatan Perlindungan Tenaga Kerja Indonesia (TKI) di Provinsi Sumatera Utara. Metode yang dilakukan dalam penelitian ini adalah metode kualitatif deskriptif yang berkaitan dengan pengumpulan data dan identifikasi. Metode analisis data menggunakan reduksi data dan instrument penelitian yaitu wawancara dan dokumentasi. Hasil penelitian ini menunjukkan bahwa Layanan Penempatan Perlindungan Tenaga Kerja Indonesia (TKI) sudah menjalankan tugas dengan kebijakan Undang-undang Nomor 39 Tahun 2004 tentang penempatan dan perlindungan Tenaga Kerja Indonesia (TKI) di luar negeri. Dalam menjalankan tugasnya ada hambatan yang dihadapi dalam memberikan perlindungan hukum kepada tenaga kerja negara.
\end{abstract}

Kata kunci: Perlindungan Hukum, Tenaga Kerja Indonesia, Provinsi Sumatera Utara

\begin{abstract}
Indonesian labor is a term for low-skilled and unskilled Indonesian citizens who work abroad in employment relations for a certain period of time with wages. Legal protection for Indonesian Workers' Rights has not gone well, the need for guidance on the meaning of labor law for Indonesia, this undermines Indonesian Workforce and eliminates job security for Indonesian workers while abroad, the obstacles to implementing Indonesian legal protection for workers are mistakes that conducted by Indonesia, namely Manpower does not report problems to the Government of Indonesia in connection with the employment of Indonesian Workers. The purpose of this research is to find out more clearly and broadly about the protection of Indonesian workers working abroad who are carried out by the terrace of the Ministry of Placement of Protection of Indonesian Workers in North Sumatra Province. The method carried out in this study is descriptive qualitative methods related to data collection and identification. Data analysis method uses data reduction and research instruments, namely interviews and documentation. The results of this study indicate that the Indonesian Labor Protection Placement Service has carried out its duties with the policy of Law No. 39 of 2004 concerning the placement and protection of Indonesian workers abroad. In carrying out its duties there are obstacles faced in providing legal protection to the state labor force.
\end{abstract} Keywords: Legal Protection, Indonesian Labor, North Sumatra Province

How to Cite: Pratiwi, V.D. \& Suharno. (2019). Implementasi UU Nomor 39 Tahun 2004 Terhadap Tenaga Kerja Indonesia. JUPIIS: Jurnal Pendidikan Ilmu-ilmu Sosial, 11 (1):1-9.

${ }^{*}$ Corresponding author: ISSN 2085-482X (Print)

E-mail: Vinnipratiwi29@gmail.com ISSN 2407-7429 (Online) 


\section{PENDAHULUAN}

Penempatan tenaga kerja ke luar negeri sering menimbulkan masalah, antara lain tenaga kerja tidak memiliki perlindungan ketika calon Tenaga Kerja Indonesia (TKI) tersebut mendapatkan masalah di negara tempat mereka bekerja. Perlunya peran serta masyarakat dalam suatu sistem hukum guna melindungi Tenaga Kerja Indonesia (TKI) yang ditempatkan ke luar negeri. Sehubungan dengan perencanaan kebutuhan tenaga kerja ke luar negeri perlu digambarkan bahwa kondisi saat ini penempatan tenaga kerja ke luar negeri masih didominasi tenaga kerja yang tidak memliki keahlian (unskilled labour).

Menurut Djumialdji (2008) tenaga kerja (buruh) harus memiliki tiga kewajibaan yang harus dilakukan, yaitu: 1) pekerja atau buruh berkewajiban melakukan pekerjaan, 2) menataati tata tertib perusahaan, 3) bertidak sebagai perkerja atau/buruh yang baik.

Salah satu penyebab kasus TKI/TKW yang menjadi korban tindak pidana adalah rendahnya tingkat pendidikan calon Tenaga Kerja Indonesia (TKI) yang mengakibatkan mereka menghadapi risiko mudah ditipu pihak lain. Mereka tidak memahami aturan dan persyaratan untuk bekerja di luar negeri. Rendahnya laporan Tenaga Kerja Indonesia (TKI) yang mengalami kasus tertentu ke pihak berwenang juga didasarkan kekhawatiran mereka karena memiliki identitas palsu bagi Tenaga Kerja Indonesia (TKI) ilegal. Banyak Tenaga Kerja Indonesia (TKI) usianya masih terlalu muda, namun demi kelancaran proses, usia di dokumen palsukan. Pemalsuan tidak hanya usia, tetapi juga nama dan alamat. Oleh karena itu, tidak mudah melacak para Tenaga Kerja Indonesia (TKI) bermasalah di luar negeri. (Wawancara dengan Bapak Dadang Agus Pitriono S.H wawancara pada tanggal 6 Aprli 2017)

Triningsih dan Ichihashi (2010) menjelaskan pemalsuan tersebut dikarenakan fakta kemiskinan, "kemiskinan adalah salah satu penentu pekerja anak di Indonesia selain faktorfaktor lain seperti usia, sector pertanian, dan pendidikan orang tua. Dalam hal kebijakan pendidikan, program yang memberikan subsidi ke sekolah dapat mengurangi insiden pekerja anak terutama di daerah pedesaan."

Ada tiga fungsi akta otentik (dalam perjanjian secara umum), yakni: 1) Sebagai bukti Tenaga Kerja Indonesia (TKI) telah mengadakan perjanjian tertentu. 2) Sebagai bukti Tenaga Kerja Indonesia (TKI) apa yang tertulis dalam perjanjian adalah harus menjadi tujuan dan keinginan Tenaga Kerja Indonesia (TKI) (TKI). 3) Sebagai bukti kepada Tenaga Kerja Indonesia (TKI) pada tanggal tertentu, kecuali harus ditentukan sebaliknya Tenaga Kerja Indonesia (TKI) telah mengadakan perjanjian. Hal ini juga menentukan bahwa perjanjian sesuai dengan kehendak Tenaga Kerja Indonesia (TKI) (Kusumohamidjojo, 1998)

Perlindungan dari Balai Pelayanan Penempatan dan Perlindungan Tenaga Kerja Indonesia (TKI) (BP3TKI) Provinsi Sumatera Utara bermaksud memberikan rasa aman kepada Tenaga Kerja Indonesia (TKI) pada setiap tahapan penempatan dimulai dari proses awal rekrut, ditempatkan kerja hingga selesai kontrak dan kembali ke daerah asal.

\section{Menurut Situmorang}

Perlindungan hukum terhadap Tenaga Kerja Indonesia (TKI) dilaksanakan mulai dari pra penempatan, masa penempatan sampai dengan purna penempatan. Perlindungan pra penempatan digunakan sebagai tempat penampungan calon Tenaga Kerja Indonesia (TKI) yang akan berangkat ke luar negeri. Perlindungan masa penempatan dilaksanakan waktu para Tenaga Kerja Indonesia (TKI) berada di luar negeri, para Tenaga Kerja Indonesia (TKI) wajib untuk melaporkan kedatangannya kepada Perwakilan RI dinegara tujuan. Perlindungan purna 
penempatan dilaksanakan disaat kepulangan Tenaga Kerja Indonesia (TKI) dari negara tujuan sampai tiba didaerah asal. Pemberian perlindungan terhadap Tenaga Kerja Indonesia (TKI) dari adanya tindakan pihak-pihak lain yang tidak bertanggung jawab dan dapat merugikan Tenaga Kerja Indonesia (TKI) dalam kepulangan.

Maka permasalahan yang dibahas dalam penulisan jurnal ini adalah perlindungan hukum calon Tenaga Kerja Indonesia (TKI) yang dilaksanakan mulai dari pra penempatan sampai dengan purna penempatan ke luar negeri menurut peraturan perundang-undangan yang dilakukan oleh Balai Pelayanan Penempatan dan Perlindungan Tenaga Kerja Indonesia (TKI) Provinsi Sumatera Utara serta hambatan-hambatan yang dihadapi BP3TKI Provinsi Sumatera Utara dalam memberikan perlindungan hukum.

Menurut Husni (2014). Calon Tenaga Kerja Indonesia (TKI) adalah setiap warga Negara Indonesia yang memenuhi syarat sebagai pencari kerja yang akan bekerja di luar negeri dan terdaftar di pemerintah kabupaten/kota yang bertanggung jawab di bidang ketenagakerjaan. Dalam penempatannya Tenaga Kerja Indonesia (TKI) di luar negeri dibekali dengan keterampilan, bahasa, sikap mental, etos kerja dan kemampuan lainnya yang diperlukan. Dalam bekerja di luar negeri diperlukan kiat sukses.

Menurut Pasal 35 UU Nomor 39 Tahun 2004 Calon Tenaga Kerja Indonesia (TKI) untuk dapat menjadi Tenaga Kerja Indonesia (TKI) yang baik harus memiliki syarat-syarat sebagai berikut: (1) Berusia sekurang-kurangnya 18 tahun kecuali bagi Calon Tenaga Kerja Indonesia (TKI) yang dipekerjakan pada pengguna perorangan sekurang-kurangnya 21 tahun, (2) sehat jasmani dan rohani, (3) Memiliki Keterampilan, (4) Tidak dalam Keadaan Hamil. (5) Calon Tenaga Kerja Indonesia (TKI) terdaftar di Dinas Tenaga Kerja di daerah tempat tinggalnya, (6) Memiliki dokumen lengkap.

Dalam pemberian perlindungan hukum untuk Tenaga Kerja Indonesia (TKI) diatur dalam UU Nomor 39 Tahun 2004 Pasal 77 yang menyatakan bahwa: 1) Setiap Calon Tenaga Kerja Indonesia (TKI) atau Tenaga Kerja Indonesia (TKI) mempunyai hak untuk memperoleh perlindungan sesuai dengan peraturan perundang-undangan, 2) Perlindungan sebagaimana dimaksud pada ayat (1) dilaksanakan mulai dari pra penempatan, masa penempatan, sampai dengan purna penempatan.

Balai Pelayanan Penempatan dan Perlindungan Tenaga Kerja Indonesia (BP3TKI) mempunyai tugas memberikan kemudahan pelayanan memproses seluruh dokumen penempatan, perlindungan dan penyelesaian masalah Tenaga Kerja Indonesia (TKI) secara terkoordinasi dan terintegrasi di wilayah kerja masingmasing Balai Pelayanan Penempatan dan Perlindungan Tenaga Kerja Indonesia (BP3TKI). Kemudahan pelayanan dilakukan bersama-sama dengan instansi pemerintahan terkait baik Pemerintah Pusat Daerah.

Oleh Negara-negara pengguna ke Indonesia telah menjadi korban tindak pidana yaitu tindak pidana permekosaan, ada sampai hamil dan ada yang trauma, tindak pidana penganiayaan, tindak pidana pembunuhan, tindak pidana penggelapan (uang gaji tidak dibayar sama sekali), tindak pidana perzinaan tanpa adanya proses hukum tuntas baik di negaranegara pengguna maupun dinegara Indonesia sesuai dengan Hukum Pidana Nasional Negara pengguna. Wahyudi dkk (2016) yang menyatakan setiap tenaga kerja mempunyai hak dan kesempatan yang sama untuk memilih, mendapatkan, atau pindah pekerjaan dan memperoleh penghasilan yang layak di dalam atau di luar negeri

Menurut Abdussalam, dkk (2016) Kasus TKI/TKW baik legal maupun ilegal 
yang menjadi korban tindak pidana di Negara-negara pengguna yang dilakukan oleh majikan yang terjadi dalam tahun 2002 sampai dengan tahun 2009 tidak lah kasus biasa. Salah satu kasus TKI/TKW sepanjang tahun 2002-2018 yaitu sebagai berikut: 1) 1 Agustus 2002 Penganiayaan di alami Arista asal Taliwang, Sumbawa. Ia dianiaya dan diperkosa majikan di Arab Saudi. Penganiayaan mengakibatkan rahang miring dan kedua kakinya patah. Tidak sadarkan diri selama empat bulan dan harus dirawat di rumah sakit karena dicekik majikannya saat berusaha untuk kembali memperkosanya, 2) 7 Januari 2009 Penganiyaan oleh majikan juga dialami oleh Keni asal Brebes, Jawa Tengah, yang bekerja di Arab Saudi. Penyiksaan meninggalkan luka bakar setrika yang hampir menutupi seluruh tubuhnya. Kedua kupingnya mengkerut. Selain memukul, majikannya juga mencongkel gigi depan. Keni juga tidak diberi makan yang cukup, 3) 16 Februari 2017 Siti Aishah asal Serang, Banten, yang menjadi tersangka pembunuh Kim Jong Nam, Kakak tiri Pemimpin Korea Utara Kim Jong Un, 4) 10 Februari 2018 Adelina Lisau asal Nusa Tenggara Timur (NTT) meninggal dunia di Rumah Sakit Bukit Mertajam menderita luka-luka ditubuhnya dan juga nanah di bagian kaki yang terkena luka bakar.

\section{METODE PENELITIAN}

Adapun lokasi penelitian ini adalah BP3TKI Provinsi Sumatera Utara di Jalan Pendidikan No: 357, Mariendal I, Provinsi Sumatera Utara, Telp: (061) 77808329, 7851960, Fax: (061) 7851960.

Sumber data menurut Suharsimi Arikunto adalah subjek dari mana data itu diperoleh (Arikunto, 2006). Oleh karena itu yang menjadi subjek dalam penelitian ini adalah peneliti sendiri, karena peneliti sendiri merupakan alat (instrument) pengumpulan data utama yang nantinya mengurai data, dan dengan peneliti itu terjun langsung kelapangan maka peneliti dapat melihat secara langsung fenomena di daerah lapangan. Objek penelitian ini adalah Balai Pelayanan Penempatan dan Perlindungan Tenaga Kerja Indonesia (BP3TKI) Provinsi Sumatera Utara Jl. Pendidikan N0: 357, Mariendal I, Provinsi Sumatera Utara.

Dalam proses pemilihan Tenaga Kerja Indonesia (TKI) sebagai responden, peneliti tidak memilih seluruh Tenaga Kerja Indonesia (TKI) yang bekerja di Balai Pelayanan Penempatan dan Perlindungan Tenaga Kerja Indonesia (BP3TKI) Provinsi Sumatera Utara disebabkan jumlah yang terlalu banyak. Untuk melengkapi data dalam penelitian ini, peneliti mengambil sebanyak 3 orang Tenaga Kerja Indonesia (TKI) untuk diwawancarai sebagai subyek responden dalam penelitian ini.

Adapun variabel penelitian ini merupakan variabel tunggal yaitu Perlindungan Hukum Terhadap Indonesia menurut UU Nomor 39 Tahun 2004. Defenisi operasional dalam penelitian ini adalah: 1) Balai Pelayanan, Penempatan dan Perlindungan Indonesia adalah suatu badan yang dibentuk oleh Presiden yang diberikan kepada calon Tenaga Kerja Indonesia (TKI) atas dasar peraturan perundangan yang berlaku agar seseorang itu terjamin hak-haknya. 2) Perlindungan hukum adalah perbuatan yang diberikan kepada seseorang atas dasar peraturan perundangan yang berlaku agar seseorang itu terjamin hak-haknya. 3) UU Nomor 39 Tahun 2004 adalah dasar hukum atau aturan aturan yang menjadi pedoman Balai Pelayanan Penempatan dan Perlindungan Tenaga Kerja Indonesia (BP3TKI).

Di dalam penelitian menggunakan data: sumber data primer dan sumber data sekunder. 1) Sumber data primer mengambil responden yang digunakan nonprobabilitas yaitu suatu teknik pengambilan sampel dimana peran peneliti sangat besar untuk mengukur sampai berapa jauh sampel yang diambil dapat mewakili populasinya. 2) Sumber 
data sekunder yang digunakan sama seperti penjelasan Ashofa (2004) yaitu bahan hukum yang memberikan penjelasan bahan hukum primer, seperti rancangan undang-undang, hasil-hasil penelitian, buku, artikel serta laporan penelitian

Teknik pengumpulan data yang digunakan adalah sebagai berikut: 1) Wawancara yang dilakukan dalam penelitian ini adalah sebuah dialog yang dilakukan oleh penulis untuk memperoleh informasi dari responden. 2) Obeservasi partisipan digunakan dalam penelitian ini yaitu untuk melengkapi data yang diperoleh dari wawancara. Observasi partisipan adalah pengamatan berperan serta sekaligus menjadi anggota resmi yang diamati (Moleong, 2002). 3) Penelitian ini menggunakan alat pengumpulan berupa buku-buku, dokumen, serta sumber lain yang relevan untuk memperoleh data dan permasalahan tentang perlindungan hukum terhadap tenaga kerja dalam keselamatan kerja di BP3TKI Provinsi Sumatera Utara.

Adapun penelitian ini menggunakan Analisis Deskriptif Kualitatif. Analisis data yang digunakan adalah reduksi data yang analisis datanya berupaya memberikan gambaran secara jelas dan konkret terhadap masalah penelitian yang dibahas secara kualitatif dan data tersebut disajikan secara deskriptif yaitu menjelaskan dan menggambarkan sesuai dengan permasalahan yang ada keterkaitannya terhadap penelitian ini. Menurut Zainuddin (2011) Penelitian yuridis normatif yang bersifat kualitatif adalah penelitian yang mengacu pada norma hukum yng terdapat dalam peraturan perundang-undangan dan putusan pengadilan serta norma-norma yang hidup dan berkembang dalam masyarakat.

\section{HASIL DAN PEMBAHASAN}

Bentuk Perlindungan Hukum Balai Pelayanan Penempatan dan Perlindungan
Tenaga Kerja Indonesia (BP3TKI) Provinsi Sumatera Utara dalam kedudukannya Balai Pelayanan Penempatan dan Perlindungan Tenaga Kerja Indonesia (BP3TKI) diatur dalam Peraturan Presiden Republik Indonesia Nomor 81 Tahun 2006 tentang Badan Nasional Penempatan dan Perlindungan Tenaga Kerja Indonesia (TKI) dalam Pasal 23, 24, dan 25.

Setiap pekerja atau buruh mempunyai hak untuk memperoleh perlindungan atas keselamatan dan kesehatan kerja, moral dan kesusilaan, dan perlakuan yang sesuai dengan harkat dan martabat manusia serta nilai-nilai agama (Pasal 86 ayat 1 Undang-Undang Nomor 13 Tahun 2003 tentang Ketenagakerjaan).

Berdasarkan hasil wawancara dengan seksi perlindungan dan pemberdayaan Balai Pelayanan Penempatan dan Perlindungan Tenaga Kerja Indonesia (BP3TKI) Provinsi Sumatera Utara (Bapak Dadang Agus Pitriono S.H wawancara pada tanggal 22 Februari 2017) beserta seksi Kelembagaan dan Pemasyarakatan Program (Bapak Amir Abdi Hakim Sihotang S.P wawancara pada tanggal 21 Februari 2017), mereka menyatakan bahwa setiap Tenaga Kerja Indonesia (TKI) yang berada di luar negeri mendapatkan perlindungan mulai dari pemberangkatan sampai kepulangan ke daerah asal Tenaga Kerja Indonesia (TKI) dan menjamin pemenuhan hak serta perlindungan Tenaga Kerja Indonesia (TKI) secara optimal di negara tujuan.

"Setiap Tenaga Kerja Indonesia (TKI) yang disalurkan oleh perusahaan dari masing-masing daerah akan mendapat perlindungan yang sama, karena BP3TKI telah berpedoman pada Undang-Undang Nomor 39 Tahun 2004 Pasal 1 point (4) yang menjelaskan bahwa Perlindungan Tenaga Kerja Indonesia (TKI) adalah segala upaya melindungi kepentingan calon Tenaga Kerja Indonesia (TKI) maupun Tenaga Kerja Indonesia (TKI) dalam mewujudkan terjadinya pemenuhan hak-hak sesuai dengan peraturan 
perundang-undangan, baik sebelum, selama, maupun sesudah bekerja." (Wawancara dengan Bapak Dadang Agus Pitriono S.H wawancara pada tanggal 6 Aprli 2017)

Perlindungan hukum terhadap Tenaga Kerja Indonesia (TKI) dalam hal perlindungan pada Balai Pelayanan Penempatan dan Perlindungan Tenaga Kerja Indonesia (BP3TKI) Provinsi Sumatera Utara meliputi pra penempatan, masa penempatan dan purna penempatan. Untuk meminimalkan terjadinya kekerasan dan perselisihan Tenaga Kerja Indonesia (TKI) terhadap majikan ataupun dengan perusahaan, maka setiap BP3TKI wajib memberikan perlindungan dan penempatan para Tenaga Kerja Indonesia (TKI) selama bekerja di Negara tujuan.

Balai Pelayanan Penempatan dan Perlindungan Tenaga Kerja Indonesia (BP3TKI) Provinsi Sumatera Utara sudah memberikan pelatihan dan pendidikan untuk calon Tenaga Kerja Indonesia (TKI) yang akan berangkat ke negara tujuan, pendidikan dan pelatihan kerja bagi Tenaga Kerja Indonesia (TKI) sesuai dengan ketentuan pada Pasal 41 dan Pasal 42 Undang-undang 39 Nomor tahun 2004 tentang penempatan dan perlindungan Tenaga Kerja Indonesia (TKI) di luar negeri yaitu Calon Tenaga Kerja Indonesia (TKI) wajib melakukan pendidikan dan pelatihan kerja sesuai dengan pekerjaan yang akan dilakukan di negara tujuan dan Calon Tenaga Kerja Indonesia (TKI) memperoleh pengakuan kompetensi kerja setelah mengikuti pendidikan dan pelatihan kerja yang diselenggarakan oleh BP3TKI Provinsi Sumatera Utara. Dengan demikian bahwa BP3TKI Provinsi Sumatera Utara sudah menerapkan Pasal 41 dan Pasal 42 Undang-Undang Nomor 39 tahun 2004 tentang penempatan dan perlindungan Tenaga Kerja Indonesia (TKI) di luar negeri.

Pemberian perlindungan dalam masa penempatan Tenaga Kerja Indonesia (TKI) pada Balai Pelayanan Penempatan dan
Perlindungan Tenaga Kerja Indonesia (BP3TKI) Provinsi Sumatera Utara di atas tidak sesuai dengan ketentuan pada Pasal 8e Undang-undang Nomor 39 tahun 2004 tentang penempatan dan perlindungan Tenaga Kerja Indonesia (TKI) di luar negeri yaitu setiap calon Tenaga Kerja Indonesia (TKI) meperoleh upah sesuai dengan standard upah yang berlaku di negara tujuan. Dengan demikian dapat disimpulkan bahwa Balai Pelayanan Penempatan dan Perlindungan Tenaga Kerja Indonesia (BP3TKI) Provinsi Sumatera Utara belum bisa menerapkan Pasal 8e Undang-Undang tentang penempatan dan perlindungan Tenaga Kerja Indonesia (TKI) di luar negeri.

Dari penelitian yang di dapat bahwa semua biaya kepulangan ditanggung oleh majikan atau perusahaan yang bersangkutan, kalaupun ada yang membiayai perjalanan sendiri disebabkan Tenaga Kerja Indonesia (TKI) tersebut memiliki masalah dengan majikannya atau melanggar kontrak perjanjian seperti Tenaga Kerja Indonesia (TKI) yang mencari majikan baru sebelum kontrak habis.

Balai Pelayanan Penempatan dan Perlindungan Tenaga Kerja Indonesia (BP3TKI) Provinsi Sumatera Utara memberikan fasilitas kemudahan dalam kepulangan Tenaga Kerja Indonesia (TKI) ke daerah asal dan memberikan fasilitas kesehatan bagi Tenaga Kerja Indonesia (TKI) yang sakit dalam perjalanan pulang ke Indonesia. Menurut Pasal 75 Undang undang Nomor 39 tahun 2004 tentang penempatan dan perlindungan Tenaga Kerja Indonesia (TKI) di luar negeri terdapat beberapa hal-hal menyangkut kepulangan Tenaga Kerja Indonesia (TKI) yang akan kembali ke Indonesia.

Berikut ini adalah beberapa hal yang menyangkut perlindungan kepulangan Tenaga Kerja Indonesia (TKI) tersebut: 1) Kepulangan Tenaga Kerja Indonesia (TKI) dari Negara tujuan sampai tiba di daerah asal menjadi tanggung jawab pelaksana 
penempatan Tenaga Kerja Indonesia (TKI). 2) Pengurusan kepulangan Tenaga Kerja Indonesia (TKI) dari Negara tujuan sampai tiba di daerah asal menjadi tanggung jawab pelaksana penempatan Tenaga Kerja Indonesia (TKI). 3) Pemerintah dapat mengatur kepulangan Tenaga Kerja Indonesia (TKI) diatur lebih lanjut dengan Peraturan Menteri. (Undang-Undang No. 39 Tahun 20014)

Pemberian perlindungan purna penempatan kepada Tenaga Kerja Indonesia (TKI) pada Balai Pelayanan Penempatan dan Perlindungan Tenaga Kerja Indonesia (BP3TKI) Provinsi Sumatera Utara di atas sudah sesuai dengan ketentuan Pasal 75 Undang undang Nomor 39 tahun 2004 tentang penempatan dan perlindungan Tenaga Kerja Indonesia (TKI) di luar negeri yaitu pemberian fasilitas kemudahan dan fasiliatas kesehatan selama kepulangan para Tenaga Kerja Indonesia (TKI) ke Indonesia, memberikan upaya perlindungan terhadap Tenaga Kerja Indonesia (TKI) dari kemungkinan adanya tindakan pihak-pihak yang tidak bertanggung jawab selama kepulangan Tenaga Kerja Indonesia (TKI), hal itu menyebabkan kerugian para Tenaga Kerja Indonesia (TKI) dalam kepulangannya.

Hambatan dalam memberikan perlindungan oleh Balai Pelayanan Penempatan dan Perlindungan Tenaga Kerja Indonesia (BP3TKI) terjadi dalam beberapa kasus penganiayaan dan pelanggaran hak Tenaga Kerja Indonesia (TKI) di luar negeri menunjukkan kurangnya persiapan Tenaga Kerja Indonesia (TKI) untuk bekerja di luar negeri. Diantaranya kendala bahasa untuk berkomunikasi. Selain itu juga karena faktor pengguna jasa Tenaga Kerja Indonesia (TKI) yang bersikap berlebihan saat menemukan kesalahan kerja TKI itu.

"Dari kasus yang dialami Tenaga Kerja Indonesia (TKI) 80\% diantaranya karena ketidaksiapan mereka bekerja di luar negeri. Sehingga para Tenaga Kerja
Indonesia (TKI) belum tahu betul tentang kerja dan kondisi Negara tujuan mereka akan bekerja, hal ini banyak menyebabkan perselisihan antara para pekerja dan majikan." (Wawancara dengan Bapak Dadang Agus Pitriono S.H wawancara pada tanggal 6 Aprli 2017)

Balai Pelayanan Penempatan dan Perlindungan Tenaga Kerja Indonesia (BP3TKI) bergabung dengan Dinsosnakertrans mengadakan bursa kerja Tenaga Kerja Indonesia (TKI) ini diharapkan dapat menjadi wahana komunikasi antara pencari kerja dan perusahaan penyalur Tenaga Kerja Indonesia (TKI). Usaha ini bertujuan untuk meminimalisir kesalahan yang berakibat kerugian saat penempatan dan penyaluran Tenaga Kerja Indonesia (TKI). Penjelasan dari seksi perlindungan dan pemberdayaan Balai Pelayanan Penempatan dan Perlindungan Tenaga Kerja Indonesia (BP3TKI) Provinsi Sumatera Utara, Bapak Dadang Agus Pitriono S.H menyatakan "bursa kerja yang dimaksudkan untuk mempertemukan para pencari kerja dan perusahaan penyalur Tenaga Kerja Indonesia (TKI)."

Dalam menjalankan perlindungan hukum, Balai Pelayanan Penempatan dan Perlindungan Tenaga Kerja Indonesia (BP3TKI) masih lemah dalam memberikan perlindungan yakni pada faktor internal. Balai Pelayanan Penempatan dan Perlindungan Tenaga Kerja Indonesia (BP3TKI) mendapatkan kendala-kendala seperti keterbatasan sarana dan prasarana dalam menunjang pelaksanaan tugas Balai Pelayanan Penempatan dan Perlindungan Tenaga Kerja Indonesia (BP3TKI) Provinsi Sumatera Utara. Dan keterbatasan anggaran dana dalam proses pelayanan kepada yang telah ditempatkan di luar negeri. Seharusnya Balai Pelayanan Penempatan dan Perlindungan Tenaga Kerja Indonesia (BP3TKI) dapat melaporkan masalah ini dan meminta anggaran penuh terhadap pemerintah agar terlaksana dengan baik sarana dan 
prasarana dalam perlindungan Tenaga Kerja Indonesia (TKI). Negara juga mempunyai kewajiban untuk melindungi warga negaranya yang tinggal atau berada diluar negari (Subhan, 2012).

Selain hambatan faktor internal, terdapat pula hambatan pada faktor ekstrnal yakni lemahnya dukungan pemerintah setempat dalam program penempatan Tenaga Kerja di luar negeri, yaitu: tidak ada APBD, lemahnya peraturan dan perbedaan hukum antara dua peraturan di dua daerah yang berbeda yaitu: adanya tumpang tindih peraturan mengenai masalah ketenagakerjaan. Seharusnya Negara dapat langsung mengambil alih dalam hal masalah ketenagakerjaan. Yusoof et al (2017: menjelaskan bahwa sikap tidak etis dari pemberi kerja dalam diskriminasi (upah) tidak hanya melibatkan diri mereka sendiri tetapi juga dari faktor-faktor eksternal yang mungkin juga berkontribusi terhadap perilaku tidak etis ini.

Pertimbangan peran negara ini hendaknya tidak menghalangi pertimbangan peran yang dimainkan oleh pengusaha, walaupun peran langsung pengusaha adalah yang kedua setelah peran negara karena peran dominan yang dimainkan oleh negara dalam mengejar industrialisasi dan pembangunan bangsa (Gall, 2014). Melihat pengaruh kedua faktor ini tarik permintaan dan pendorong biaya mempengaruhi hasil-hasil ketenagakerjaan (Chowdhury et al, 2009).

\section{SIMPULAN}

Balai Pelayanan Penempatan dan Perlindungan Tenaga Kerja Indonesia (BP3TKI) belum maksimal dalam memberikan perlindungan hukum terhadap Tenaga Kerja Indonesia (TKI) diluar negeri. Karena adanya kendala yang dihadapi Balai Pelayanan Penempatan dan Perlindungan Tenaga Kerja Indonesia (BP3TKI) yakni keterbatasan sarana dan prasarana dalam menunjang pelaksanaan tugas dan kurangnya dukungan pemerintah dalam memberikan anggaran. Dan kurangnya pengarahan tentang arti bagi para Tenaga Kerja Indonesia (TKI), hal ini dapat mempersulit rasa aman bagi para Tenaga Kerja Indonesia (TKI) diluar negeri.

Adapun hambatan pelaksanaan perlindungan hukum terhadap Tenaga Kerja Indonesia (TKI) yakni kesalahan yang dilakukan oleh Tenaga Kerja Indonesia (TKI), tidak melaporkan permasalahannya kepada pemerintah Indonesia di tempat Tenaga Kerja Indonesia (TKI) bekerja, pendidikan para Tenaga Kerja Indonesia (TKI) yang masih rendah. Dan perlindungan hukum atas hak-hak Tenaga Kerja Indonesia (TKI) dalam bekerja belum berjalan dengan baik.

\section{DAFTAR PUSTAKA}

Abdussalam. (2016). Hukum Ketenagakerjaan (Hukum Perburuhan). Jakarta: PTIK

Arikunto, S. (2006). Metodologi Penelitian. Jakarta: PT. Rineka Cipta

Ashofa, B. (2004). Metode Penelitian Hukum. Jakarta: PT.Rineka Cipta

Asikin, Z. dkk. (2008). Dasar-dasar Hukum Perburuhan. Jakarta: PT Raja Grafindon Persada

Chowdhury, A., Islam, I. \& Tadjoeddin, M. Z. (2009). Indonesia's Employment Challenges: Growth, Structural Change and Labour Market Rigidity. EJEAS, 8(1) 31-59. Retrieved From:

https://www.researchgate.net/publication/ 44190572 Indonesia\&\#39;s Employment C hallenges Growth Structural Change and La bour Market Rigidity

Djumialdji, F. X. (2008). Perjanjian Kerja. Jakarta: Sinar Grafika

Gall, G. (2014). The Development of The Indonesian Labour Movement. The International Journal of Human Resource Management, 9(2) 09855192. Retrieved From:

https://www.researchgate.net/publication/23282 8606 The development of the Indonesian 1 abour movement

Moleong, L. (2014). Metodologi Penelitian Kualitatif. Bandung: PT Remaja Rosdakarya

Husni, L. (2014). Pengantar Hukum Ketenagakerjaan. Jakarta: PT Raja Grafindo Persada

Kusudmohamidjojo, B. (1998). Dasar-dasar Merancang Kontrak. Jakarta: Gramedia Widiasarana 
Subhan, H. (2012). Perlindungan TKI pada masa pra penempatan, selama penempatan dan purna penempatan "badan pembinaan hukum nasionak kementerian hukum dan hak asasi manusia". Jakarta

Situmorang, B. (2013). Pengkajian Hukum tentang Tanggung Jawab Lembaga Pengarah Tenaga Kerja (PPTKIS). Jakarta: Badan Pembinaan Hukum Nasional Kementrian Hukum dan HAM RI

Triningsih, N. \& Ichihashi, M. (2010). The Impact of Poverty and Educational Policy on Child Labor in Indonesia. JEL Classification, 138(15). Retrieved From: https://home.hiroshima-u.ac.jp/ichi/PaperChildLabor-Nina-

Wahyudi, E. dkk. (2016). Hukum Ketenagakerjaan. Jakarta: Sinar Grafika
Yusoof, S., Zuber, F., Mansur, H., Zamziba, N., \& Toriry, S. (2017). Wages of Labour Discrimination: Case Study on Nike Company Indonesia. International Journal of Academic Research in Public Policy and Governance, 4 (1) 2312-4040. Retrieved From: http://hrmars.com/hrmars papers/Wages of Labour Discrimination Case Study on $\mathrm{Ni}$ ke Company Indonesia.pdf

Zainuddin, A. (2011). Metode Penelitian Hukum. Jakarta: Sinar Grafika

Undang-undang No. 13 Tahun 2003. Undangundang Ketenagakerjaan 2003. Jakarta:Sinar Grafika

Undang-undang Republik Indonesia Nomor 39 Tahun 2004 tentang Tenaga Kerja Indonesia (TKI) di Luar Negeri. 